\title{
CORRIGENDUM
}

\section{SPAG5 upregulation predicts poor prognosis in cervical cancer patients and alters sensitivity to taxol treatment via the mTOR signaling pathway}

\author{
L-J Yuan, J-D Li, L Zhang, J-H Wang, T Wan, Y Zhou, H Tu, J-P Yun, R-Z Luo, W-H Jia and M Zheng \\ Cell Death and Disease (2015) 6, e1784; doi:10.1038/cddis.2015.163; published online 11 June 2015
}

Correction to: Cell Death and Disease (2014) 5, e1247; doi:10.1038/cddis.2014.222; published online 22 May 2014

Since the publication of this paper the authors have noted an error in Figures $2 b$ and $c$. The position of the western blot labels 'siNC'and 'siSPAG5' was incorrect. This has now been rectified, the correct figure is shown below and the corrected article appears online together with this corrigendum.

The authors would like to apologize for any inconvenience this may have caused. a
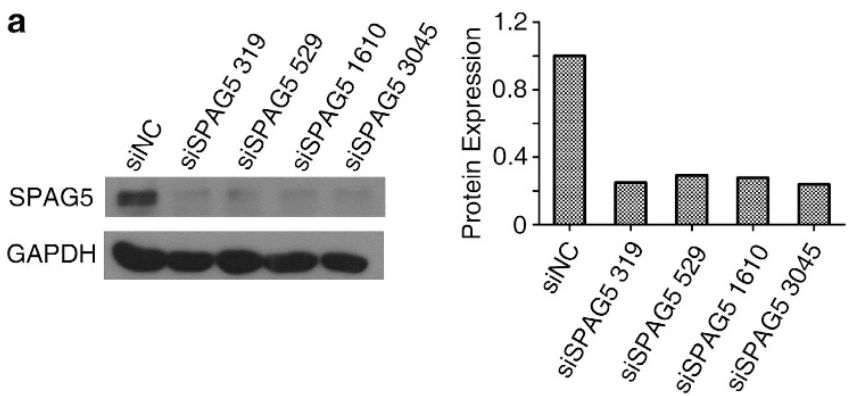

b
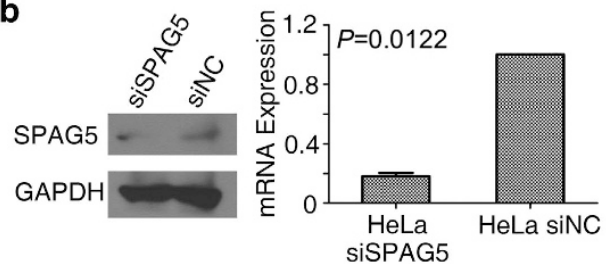

C
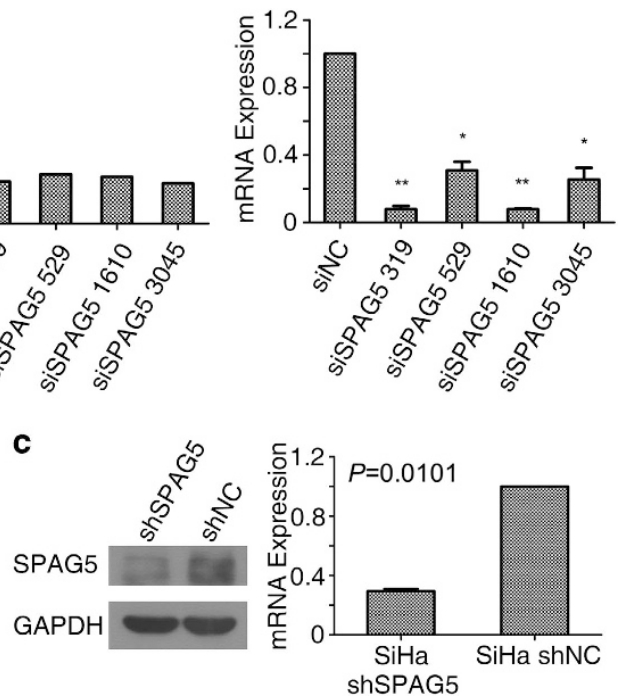

Figure 2 SPAG5 knockdown efficiency in cervical cancer cell lines. (a) Western blot of siRNA specific to SPAG5 knockdown efficiency in SiHa cells (left), gradient analysis (middle); mRNA expression (right) was detected by qRT-PCR. (b) Transient knockdown reflected in levels of SPAG5 protein (left) and mRNA (right) in HeLa cells. (c) SPAG5 expression in shSPAG5 lines detected by western blotting (right) and qRT-PCR (left) 